\title{
Application Research on Flipped Classroom Model for Educational Technology Major
}

\author{
Wei Xiao ${ }^{\mathrm{a}}$, Mei Bie ${ }^{\mathrm{b}}$ and Yunzheng Zhang ${ }^{\mathrm{c}}$ \\ Institute of Media and Communications, Changchun Normal University, Jilin Province, P.R. China \\ aiamxiaowei_@163.com, bbie-mei@163.com, ‘624596731@qq.com
}

Keywords: Flipped Classroom Model; Educational Technology Major; Active Learning

\begin{abstract}
Flipped Classroom teaching model re-plans the learning time, reversing the process of knowledge transfer and knowledge internalization, creating a new communication mechanism conducive to the interaction between teachers and students, students and students, which has created a new possibility for the reform of classroom teaching in universities. The research about how to apply the flipped classroom teaching model for educational technology major carried out for four courses in fall semester of 2016. Nearly 100 students in three grades are involved in the questionnaire, formal and informal interview. Most of the students,84.95\%,believe that the flipped classroom teaching model could facilitate the active learning and the student-centered teaching. The present study confirmed that the model benefits from screening appropriate teaching content, rational grouping, and the instructional design.
\end{abstract}

\section{Introduction}

The era of new paradigm of education is approaching, learning is not only internal and individual activity, but also collective, critical, collaborative and online process. In this sense, flipped classroom as a new teaching model arises. Re-planning the time inside and outside the classroom is the typical character: prior to the class, students will pre-review, and study the learning content through the video, e-books or other learning materials provided by teachers, and the valuable time in class is used for conducting the students-centered active learning activities, such as question time, summary of the study, collaborative inquiry and so on[1]. What is clear is that the advantages of the flipped classroom model: the learners conduct independent, personalized learning according to their own learning ability pre-class; the in-depth level of learning interaction with learning companions, and teachers will be promoted in the classroom; the necessary knowledge supplement can be done after class in case of any omitted, thus to deepen understanding and prevent the knowledge gap at the same time.[2].

The origin for the flipped classroom teaching model to draw the attention is in "Khan Academy", which was primarily implemented in the primary and middle schools. In recent years, more and more researchers have begun to pay attention to its application in the field of higher education. Òscar Flores, Isabel del-Arco et al combed and analyzed the teaching evaluation of the teachers and students at the university, and pointed out the promoting role of the flipped classroom teaching model in changing the roles of teachers and students, and motivate the students' interest in the curriculum, etc. Yan Qian, Xiaohui Chen, conducted quantitative and qualitative analysis of the flipped classroom of the two classes at the University of Southern California based on RCOI, and they put forward nine principles of flipped classroom according to the survey data. Through a series of empirical research, Xiulin Ma, Guoqing Zhao et al summarized potential advantages of the flipped classroom in the instruction of the information technology common course, as well as its limitations[3].

\section{Research on Flipped Classroom Model for Educational Technology Major}

The project team carried out the blended flipped classroom model for four courses of the educational technology major: the basic programming design (freshman year), JAVA program design and application (sophomore year), Flash Foundation (sophomore year) and audio and video 
digital technology (third grade) of Changchun Normal University in fall semester of 2016. The questionnaire forms about the learning satisfaction of the students were investigated at the end of the term. Most of the students,84.95\%, believe that the flipped classroom teaching model could facilitate the active learning and the student-centered teaching, shown as Fig 1.

\title{
Do you think the flipped classroom model will help the active learning and stududent-centered teaching?
}

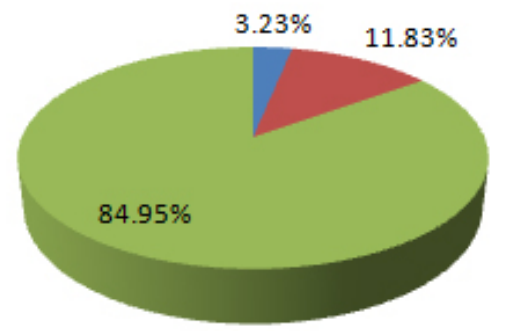

\author{
No Effect \\ A little help \\ More help
}

Fig 1. Answers of the question

The present study confirmed that the model benefits from screening appropriate teaching content, rational grouping, and the instructional design.

Screening Appropriate Teaching Content. This study is to explore the appropriate application of the flipped classroom teaching model to the courses of educational technology major in the higher normal colleges and universities, rather than completely discard traditional teaching-oriented classroom teaching model, it is to discuss what kind of learning content are applicable to the flipped classroom teaching model based on detailed analysis.

Introduction, basic concepts, basic principles and similar contents are not suitable for the application of flipped classroom teaching model. Previously, some scholars have shown that students of introductory courses do not have a good understanding of what they are studying and the unclear learning tasks would lead to their frustration [4]. In this regard, for the content screening of each course, the basic, conceptual knowledge is excluded at first, such as: introduction to the algorithm; data types, operators and expressions of the basic programming design; Object-oriented overview of the course of Java programming design and application, and so on. These basic concepts, basic algorithm should be delivered to the students clearly and accurately at the beginning, so as not to affect the learning of the follow-up knowledge due to the understanding bias.

In contrast, the students have a certain understanding of the whole course in the medium term. Some operational examples become the first choice for exploring the flipped classroom teaching model at this time. The Screen Video Experts or other similar screen recording software is used to record a complete demo of examples, while offering some topical exercises, together with operational guidance, or a variety of excellent teaching resources on the network, so that the students have the space for the connected thinking. For example: simple sort of the basic programming design, mask animation of Flash foundation and so on. It was learned from the informal interview after class that the students have high interest and satisfaction in the flipped classroom implemented by such content, and they were willing to have the independent exploration after completing the basic teaching tasks, especially for the learning task with some challenges. On the one hand, this can lead to deeper levels of learning interest; on the other hand, those students complete the more difficult learning tasks are happy to share with others, which to some extent contributed to the meaningful cooperative learning.

Rational Grouping To Mobilize Students With Learning Difficulties. Although many studies have shown that the flipped classroom teaching model can indeed improve students' academic performance and participation in the learning process, while also developing students' ability of information screening, teamwork, critical thinking, self-management and self-evaluation of the learning process, the pre-class learning is one of the most important factors for the success of flipped classroom. Some students have difficulty in completing the pre-class learning tasks because they are accustomed to traditional passive learning methods or because they are not good at independent learning. Regardless of any reason, it is difficult for those students who have not 
completed pre-class learning to achieve the learning objectives of this course.

In order to enable those students with insufficient learning ability, inappropriate learning methods, or unclear learning direction can also be attracted to the pre-class learning. First of all, it's necessary to do a good job in learner analysis, and make rational grouping according to the learning characteristics of students. Different students have the different self-disciplines, and their acquisition ability to the pre-class information is not the same, the group allocation cannot be simply carried out according to the student ID or the random distribution based on the dormitory number. It's essential to have the understanding of students' learning ability in advance. The selected team leaders of the learning groups should be good at self-learning, planning and organization. Secondly, it's necessary to arrange the basic tasks each student needs to complete for the submission, as well as the group tasks with slight difficulties and challenges. We can carry out random questioning, or prearrange individuals or individual groups to demonstrate learning tasks. In addition, where possible, one or two teaching assistants can be deployed to take charge of tutoring and answering in class, which will contribute to the active individualized learning.

Emphasis On Teaching Planning And Design In Various Links. The flipped classroom teaching model is not merely the re-profiling of teaching time, the core point is the thorough implementation of "student-centered" teaching philosophy, and the corresponding instructional approaches, teaching strategies and every links of the overall teaching structure, so as to achieve the expected learning objectives.

Design Of Pre-Class Learning Materials In A Students' perspective. The learners' learning style and learning needs should be comprehensively considered when designing pre-class learning materials. Teachers should always prepare the materials from the perspective of students, and remind themselves that students will complete their learning independently without the guidance of teachers. Under normal conditions, in order to avoid the occurrence of learning burnout, the video data should not be tedious, and the knowledge points should be refined into short, unabridged and correlative units. The appropriate play duration is 20 to 30 minutes, sand the overall browsing time of learning materials is no more than 2 hours. The video should be play normally, besides, audio and video should be displayed smoothly and clearly. In addition to the videos made by teachers, some excellent micro courses are also very popular with students.

Most of the time, teachers will inevitably deem that some knowledge point is very simple or has been explained before, so they ignore it directly, without realizing that it's still difficult for part of the students. In order to make ensure that each student is able to master the pre-class learning content, the students are required to provide feedback of the learning materials, meanwhile, special attention should be paid to the opinions and suggestions given by those students who are incommunicative in the classroom. According to the feedback, materials should be screened, sorted and constantly improved for subsequent use.

Proper Assistance In Class. More of the precious class time is used to improve the students' speculative thinking ability. Teachers always guide and control the trend of the entire discussion, make unified explanation for common questions and answer the personalized questions proposed by groups or individuals at the critical moment, thus truly promoting deep learning. Proper assistance means that students are given certain space for reflection and analysis, and teachers provide proper and real-time guidance to motivate students' intra-group and between-group interaction. Compared with foreign students, Chinese students are mostly introverted and weak in classroom debates and independent exploration. Hence, in dealing with learning difficulties, students should firstly be encouraged to attempt to seek solutions from learning materials, online learning resources and forum posts, secondly, they can cooperate and discuss with their learning companions. Only when difficulties still exist after adequate thinking, will teachers answer the question and clear up confusion. Such scientific inquiry ability, cooperation ability and autonomous learning ability can be cultivated in the flipped classroom teaching model, this is just where significance of implementation of the model lies in.

Facilitate Review And Reflection After Class. After class, the students are supervised to check and modify the documents submitted before class, conduct review and reflection on the whole 
learning process and resubmit the learning outcomes. Meanwhile, developing questions are assigned to promote further internalization, extension and sublimation of knowledge and skills. After pre-class information learning as well as discussion, communication and cooperative learning in class, students are capable of understanding and mastering the learned knowledge and they have acquired the operating skill. However, based on the learning theory of connectivism, the essence of learning is a kind of network ties and network creation. The knowledge points are not isolated and separated, but mutually connected. In particular, the connections between the knowledge points of computer-based courses is closer. The assignment of comprehensive practical tasks after class helps students to learn new knowledge critically, and integrate the knowledge into the original cognitive structure to form meaningful connection between the knowledge points. Teachers should carry out induction and conclusion on problems occurred in the whole teaching process after class, rethink the deficiencies and enrich the teaching courseware as well as their teaching experience.

Teaching Ideas And Financial Support. In addition to undertaking normal teaching tasks, teachers need to spend a lot of extra time and energy producing flipped classroom related videos, scheduling learning tasks, designing theme activities, etc. The task of teaching preparation is onerous, so the need for corresponding supports in ideas and funds provided by the school is greater than ever. Firstly, the support of hardware and software should be provided, mature web-based teaching platform be built and favorable devices for screen capture, picture recording and taping be offered, so as to facilitate the successful developing of the teaching model; secondly, a series of faculty trainings covering instructional theories and educational technology should be carried out, so that teachers can learn new teaching ideas and advanced intellectual technology, and constantly improve their education and teaching methods; in addition, if the conditions permit, more research grants should be put into teaching reform, interschool discussions on teaching practice, especially discussions conducted by both domestic and foreign colleges should be strengthened, and the domestic teaching reform in higher education will be further deepened.

\section{Summary}

The flipped classroom teaching model re-plans the learning time and establishes autonomous collaborative learning environment as well as diversified interactive communication mechanism, so as to create a new possibility for the class teaching reform in universities, hence, the model is an emerging class teaching paradigm and truly realizes student-centered teaching philosophy. Although this model is not mature and still remains in the stage of exploration and practice, numerous studies, including this research, have shown the promoting role of the model in learning and the potential space for its development.

\section{Acknowledgement}

This work was financially supported by the 12th Five-years Plan of Jilin Province Educational Scientific Research Leading Group (Project No. ZD15126), and Jilin Province Association of Higher Education (Project No. JGJX2015D134).

\section{References}

[1]T.T. Long, J. Logan, M. Waugh, Students' Perceptions of the Value of Using Videos as a Pre-class Learning Experience in the Flipped Classroom, Tech Trends, 60(2016)245-252.

[2]Z.L. Wu, L. Zhao, Primary Investigation on Flipped Classroom Teaching Model Based on Web-based Learning Space, China Audiovisual Education, 4(2014) 121-126.

[3]Oे. Flores, I.D. Arco, P. Silva, The flipped classroom model at the university: analysis based on professors' and students' assessment in the educational field, Journal of Educational Technology in Higher Education, 13(2016)1-12.

[4]Y. Qian, X.H. Chen, Design Philosophy and Enlightenment of Flipped Classroom in University 
of Southern California, China Audiovisual Education, 6(2015) 99-103.

[5] X.L. Ma, G.Q. Zhao, T. Wu, Empirical Study on Flipped Classroom Teaching in College Information Technology Common Required Courses, Journal of Distance Education, 1(2013) 79-85.

[6] Z.Y. He, Y.F. Ou, Q. Cao, Enlightenment of Flipped Classroom Teaching Model in American Colleges, Research in Higher Education of Engineering,2(2014)148-151.

[7] M.X. Zeng, Q.P. Zhou, G.M. Cai, X.B. Wang, Y.M. Yan, Y. Huang, Y.P. Yang, Study on Flipped Classroom Teaching Model in Software Development Courses, Research and Exploration in Laboratory, 33(2014)203-209.

[8] Q.C. Lu, Thinking of Flipped Classroom: Demonstration and Reflection, E-education Research, 8(2013)91-97.

[9] W.W. Qin, Flipped Learning: a New Paradigm of Class Teaching Reform, E-education Research, 8(2013)84-90. 